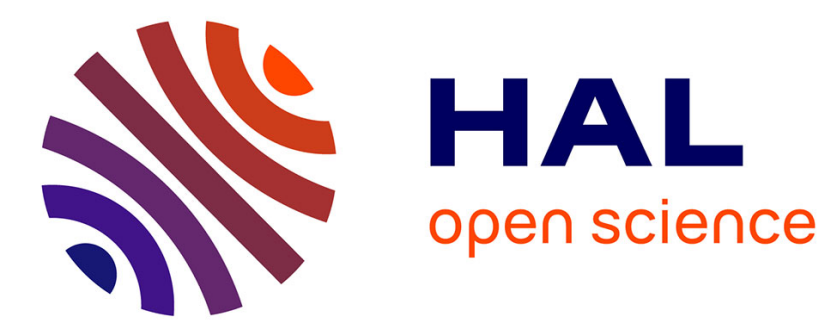

\title{
Dynamic Coupled Electrical and Thermal Model for PV-T Solar Energy Collectors
}

N. Msirdi, Nacer K M'Sirdi, Mohamed Benabdellatif, Giuseppe Marco Tina, Aziz Naamane

\section{- To cite this version:}

N. Msirdi, Nacer K M'Sirdi, Mohamed Benabdellatif, Giuseppe Marco Tina, Aziz Naamane. Dynamic Coupled Electrical and Thermal Model for PV-T Solar Energy Collectors. EFEA 2018, Nov 2018, Valencia, Spain. hal-01927535

\section{HAL Id: hal-01927535 https://hal-amu.archives-ouvertes.fr/hal-01927535}

Submitted on 27 Nov 2018

HAL is a multi-disciplinary open access archive for the deposit and dissemination of scientific research documents, whether they are published or not. The documents may come from teaching and research institutions in France or abroad, or from public or private research centers.
L'archive ouverte pluridisciplinaire HAL, est destinée au dépôt et à la diffusion de documents scientifiques de niveau recherche, publiés ou non, émanant des établissements d'enseignement et de recherche français ou étrangers, des laboratoires publics ou privés. 


\title{
Dynamic Coupled Electrical and Thermal Model for PV-T Solar Energy Collectors
}

\author{
Nacer K M'Sirdi*, Mohamed BenAbdellatif*, Giuseppe Marco Tina ${ }^{\dagger}$ and Aziz Naamane* \\ *Aix Marseille University, CNRS, Universite de Toulon, LIS UMR 702013397 \\ LIS - SASV and HyRES Lab 13399 Marseille, France. Email: nacer.msirdi@Lis-lab.fr \\ $\dagger$ University of Catania, Electric, Electronics and Computer Engineering Department, V.le A.Doria n.5 , 95125 \\ Catania, Italy
}

\begin{abstract}
This paper proposes a nonlinear state space model of a hybrid Photo-Voltaic /Thermal (glazed and unglazed PV/T) system taking into account the coupling of the electrical and the hydraulic circuits. A real time behavioral model is presented as Variable Structure Automatic System (VSAS), for simulation analysis and PV/T design optimization. The proposed model is appropriate for prediction, monitoring, control and can be used for diagnosis and the system Remaining Useful Life span increase. The analysis of the energy balance of the PVT system in its environment, leads to propose a new Maximum Life Span Power Point (MLSPP) to be used instead of the simple MPP to increase the life cycle of the PVT system.
\end{abstract}

Index Terms-PV/T system modeling, analysis and optimization, Variable Structure Automatic System, PVT state space model, Maximum Lifespan Power Point, MLSPP.

\section{INTRODUCTION}

The solar energies (Electrical and Thermal) are more and more used to exploit renewable energies. The hybrid photo voltaic and thermal (PV/T) systems are used in several applications like heating systems [1], [2], [3], water heating [4], [5] and the water pumping [6], [7]. Integrated photo-voltaic and thermal systems have proved to have better performance and efficiency [8].

Several PVT structures have been considered and studied in literature [9], [10], [11]. Hybrid PVT panels combine several advantages:

- the covered surface allows more energy production (electrical and heat) compared to the classic PV panels

- the PVT system ensures uniform architecture roof.

- possibility of reducing the cost of facilities [12].

The hybrid photo-voltaic thermal energy collectors are, in general, constructed by placing photo-voltaic solar cells directly over an absorber plate with a fluid circulation as thermal collector or solar water heater.

The proposal of solutions by Hybrid Renewable Energy Systems (HyRES) namely solar collectors PVT systems is increasing and seems more promising as the proposed technologies are more and more efficient [13]. Intelligent EMS (Energy Management Systems) are then required for such systems to manage harnessed energy and then their behavior modeling becomes crucial [14]. This clearly imposes the use of Information and Communication Technologies, by developing models, real time simulation, optimization, diagnosis,prediction and control [15].
Many technological investigations reported in literature show that the efficiency increases with Hybrid systems [16]. The electrical power output of the PV cell depends on its operating temperature. The temperature may be controlled by action on the thermal energy collector [1].

\section{A. Context and motivation}

Despite the existence of numerous papers exploring PVT systems, only few of them are oriented for the design optimization taking into account all the transient behavior effects. The optimization must take into account, not only the efficiency but, also the lifespan for the economical purpose. They are focused on the experimental evaluation of the system performances and efficiency

All the models, presented in literature, are interesting for some special purposes like evaluation of the efficiency of PVT types, or the structures, or the application performance. The models are often partial and extracted from data analysis and measurements to get efficiency representation and comparison.

None of the models is complete enough to give dynamic state space systems and transients behavior, for complete realistic dynamic simulation. The model required for real time simulation has to describe the complete non linear dynamics (including transient effects) [17], [11]. It must allow real time feedback control with several objective functions, like power optimization with care to the process maintenance and Remaining Useful Life Time (RUL).

To obtain an accurate model of the PVT module and to study its real-time characteristic with the variation in temperature and irradiation, a dynamic model must be developed and analyzed. We propose a more detailed thermal model of PVT panels where we take into consideration the external heat sources, operating conditions, internal heat sources, and heat dissipation.

Our objective is that the model must allow to drive the system to an operational point (the Maximum Life Span Power Point: MLSPP) with maximum efficiency while keeping the process in healthy comfortable situation for the process.

\section{B. Contribution}

This work gives a complete PVT Non Linear model for glazed and unglazed PVT collectors, written in state space 
form, able to clarify the rationale behind the electricalhydraulic-thermal couplings. This, as the main objective of this paper, is useful for real time simulation, analysis, optimization, prediction and control.

The focus of this paper is to develop a nonlinear dynamic model which explicitly describes the PV, hydraulic, thermodynamic, electrical and thermal couplings in the system and gives realistic behavior and real time representation in control point of view.

The proposed model provides the system dynamic states evolution (for thermal, hydrodynamic and PV coupled effects) of the various system components and describes well the transient behavior to allow deep performance analysis (of thermal/electrical coupling) and robust control and diagnosis. It allows to understand and manage thermal and PV coupling. This allowed us to define an interesting operation point, the Maximum Life Span Power Point (MLSPP) which allows to increase the RUL (Remaining Useful Life) of the PVT system, by managing the PV cells heating and limiting the cells temperature to acceptable values regarding to their State of Health $(\mathrm{SoH})$. The developed models for glazed and unglazed PVT are validated using actual data. They are then used for numerical prototyping and we have compared, in simulations, their efficiency and performance when varying the systems physical parameters.

\section{BACKGROUND, AsSUMPTIONS AND FORMULATION}

\section{A. Background}

In fact, the solar energy is converted into electrical as well as thermal energy from a PVT module. The thermal energy is transmitted through convection, conduction, and radiations, and this varies with the PVT design structure, the angle at which they are installed, speed of the wind, cooling technique, etc.

A PVT panel, from a thermal point of view, can be seen as a flat affected by several heat fluxes that affect its temperature. It receives solar irradiation, transfers one part to the circulating fluid and evacuates dissipated thermal power, to its environment. Thus, it is obvious that these changes will affect the output voltage and the Maximum Power supplied by the PV module.

Fact 1. As the temperature plays an important role in the $P V$ behavior and degradation [18] it must be analyzed more deeply. Then it is necessary to develop a dynamic (time varying) model of PVT system avoiding use of rough fixed estimation of operation temperature and efficiency coefficients.

Developing a thermal model allows us to understand thermal behavior of the PV system and to use it with parsimony and increase its life time. A validation of such thermal model for a simple PV is given in [18].

All the literature models assume separability of thermal and photo-voltaic subsystems (thanks to the difference of their (rise) time constants). They give in general separate, partial effects modeling and analysis which are confirmed by experimental tests and / or evaluation of the efficiency (thermal or electric).
In the following section we summarize the considered heat transfer and conversion, then we will gather all the dynamics to propose a one dimension Nominal Dynamic Model. Doing this, we will avoid the use of roughly defined estimations and try to be as precise as possible without going trough excessive details. The used assumptions will be detailed in order to allow further extension of this model.

\section{B. Operating Conditions and PVT}

In what follows, we describe more or less the energy sources and the near environment effect on the panel temperatures considered in the literature PVT models.

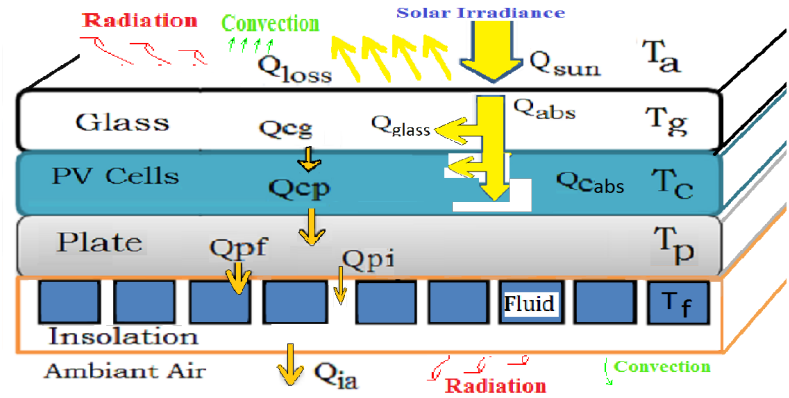

Fig. II.1. The general structure of a glazed PV/T collector

The hybrid PV/T system is, in general, composed by several layers (see figure II.1 for glazed PVT) on which we consider a node for temperature evaluation. The hybrid collector is composed by a transparent glass, a photo-voltaic module which converts radiation into electricity and a metal plate attached to the rear cells using a thin adhesive layer' Tedlar' for absorbing heat. A coil, fixed to the back of the plate allows the heat exchange with the coolant fluid. To reduce heat losses, one layer is used for insulation.

\section{Some Modeling Assumptions}

\section{Assumptions}

- The temperature is estimated in a point at the middle of the corresponding layer (node) and assumed to be homogeneous (the layer averaged temperature). The temperature gradient is not considered in the layers. $T_{a}$ is temperature of ambient air in ${ }^{\circ} \mathrm{C}, G$ the irradiation in $W . m^{-2}$ and $T_{c}$ is estimated temperature of the cell in ${ }^{o} \mathrm{C}$.

- The edges are well insulated; Thus the edge losses are negligible.

- The heat transfer coefficients depend on many parameters: The wind velocity, the air density, the panel tilt angle, humidity and the dimensions of the panel. Although these factors may substantially affect the loss coefficients, their effect on the resulting absolute cell temperature is assumed small. For simplicity, the loss coefficient is assumed constant, which neglects the effect of these factors, such as wind speed, humidity, and temperature.

- The heat conduction is neglected, in general, because the panel nearly presents no contact to solids. The heat convection occurs on the front, back, and edges 
panel surfaces. Let $h_{g a}$ be a heat transfer coefficient in $W . m^{-2} K^{-1}$. The heat convection losses, from the glass to ambient air, is $Q_{h c o n v}=h_{g a} \cdot A_{g} \cdot\left(T_{g}-T_{a}\right)$.

- The radiation occurs from the front and the back surfaces to ambient air. The thermal radiation flux is expressed, in average, by the following formula, where $\epsilon_{g}$ is the glass emissivity, $\sigma$ is the Stephan-Boltzmann constant $5.67 \cdot 10^{-8} W \cdot m^{-2} \cdot K^{-4}$, and $T_{g}$ is the average Temperature of PV panel glass in $\mathrm{K}$. The front surface emissivity is taken as 0.9 [19] the back surface emissivity is taken as 0.84 [20]. Radiation from the glass to ambient air, is

$$
\dot{Q}_{r a d}=\epsilon_{g} \cdot \sigma \cdot A \cdot\left(T_{a}^{4}-T_{g}^{4}\right)
$$

- The heat losses from the glass to ambient air, by convection $Q_{h c o n v}$ and radiation $Q_{\text {rad }}$, are then cumulated: $Q_{\text {Hloss }}=\sigma \cdot \varepsilon_{g} \cdot\left(T_{g}{ }^{4}-T_{a}{ }^{4}\right)+h_{g a} \cdot A_{g} \cdot\left(T_{g}-T_{a}\right)$

- $Q_{c g}=h_{c g} \cdot A_{g} \cdot\left(T_{g}-T_{c}\right)$ heat exchange from the glass to the PV cells.

- $h_{c p}$ is the heat transfer factor from the cells to the plate. $h_{c g}$ is the conduction thermal transfer coefficient from the glass to the cells. $Q_{c p}=h_{c p} \cdot A_{p} \cdot\left(T_{c}-T_{p}\right)$ heat exchange from the plate (temperature $T_{p}$ ) to the PV cells. $\mathrm{h}_{\mathrm{cp}}=\frac{\lambda_{c}}{e_{c}}$ conduction heat transfer coefficient between cells and the plate. $\mathrm{h}_{\mathrm{ca}}=5.67+3.8 v_{w}$ conduction heat transfer coefficient between cells and the ambient air.

Let $m_{p}, c_{p}$ be the plate mass in $k g$ and thermal specific heat respectively. The radiation coefficient from cells to glass cover is $h_{\text {rgc. }}$. It can be considered as null if the cells are fixed on the glass.

- The thermal convection flux from the glass and from the back surface (insulation) to ambient air can be expressed by the following formula, where we note $\alpha_{g}$ the absorption factor and $h_{i a}$ the coefficient of convection transfer from insolation layer to the ambient air.

$$
Q_{g c o n v}=h_{g a} \cdot A_{g} \cdot\left(T_{g}-T_{a}\right)+h_{i a} \cdot A_{i} \cdot\left(T_{i}-T_{a}\right)
$$

- $Q_{i a}$ describes the losses in contact of insulation to environment air.

$$
Q_{i a}=h_{i a} \cdot A_{i} \cdot\left(T_{i}-T_{a}\right)
$$

- The power generated by the PV panel $P_{\text {elec }}$ depends on temperature and its operating voltage $\mathrm{V}$ and $\mathrm{I}$ the generated PV current.

Several times, in literature, empirical formulas are considered to get an estimate of the cells temperature using the PV module temperature and some defined PVT operating temperature (as a reference value) [3].

Definition 2. The NOCT is defined as the measured cell temperature for an ambient temperature of $20^{\circ} \mathrm{C}$, an irradiation of $800 \mathrm{~W} \cdot \mathrm{m}^{-2}$ and a wind speed of $v_{w}=1 \mathrm{~m} \cdot \mathrm{s}^{-1}$. An empirical estimation of the cell temperature is

$$
T_{c}=T_{a}+\frac{N O C T-20}{800} \times G
$$

Definition 3. The heat convection transfer coefficient (from the glass to ambient air) is correlated to the wind velocity $\left(v_{w}\right.$ in $\left.m . s^{-1}\right)$. The convection transfer to the ambient air $h_{i a}$ is very often estimated (using some approximation) by the following formula [21][22] $h_{i a}=h_{\text {wind }}=5.7+3.8 * v_{w}$.

Fact 4. The NOCT is only a roughly calculated estimation or approximation defined as a reference in laboratory evaluation tests. The PV module, in general, does not operate always under this (steady state) temperature value (NOCT) and under fixed temperature and irradiation.

This is because between sunrise and sunset, the ambient temperature $T_{a}$ and the solar irradiation $G$ may vary over a wide range depending on the weather conditions. Although the cell temperature $T_{c}$ mainly depends on the ambient air temperature, the wind, and radiation. It is affected also by the near heat sources and transfer. All these variables and parameters have values that may vary over a wide range, depending on the atmospheric condition, geographic location, etc.

\section{Models of PVT Systems}

\section{A. Inputs and Outputs of the PVT system}

The system takes as input the Irradiance $G$, the ambient temperature $T_{a}$, the relative humidity $R_{H}$, and the cells operating voltage $V_{P V}$. The operating conditions of the PV panel (operating voltage and temperature) directly affect the output generated power. Let us consider a glazed PVT system in the analysis.

Let us note the temperature of each layer at its node: $T_{g}$ is the glass temperature in $K, T_{c}$ the cell temperature, $T_{p}$ temperature of the plate and $T_{f}$ is the coolant fluid temperature (in $K$ Kelvin). Let $T_{i}$ be the temperature insulation part. As output we can consider the cells and the fluids temperatures and may be some other one.

The incident irradiation is the main energy source (input) that contributes to heating the panel. The quantity $Q_{a b s}=$ $\dot{Q}_{\text {sun }}-Q_{\text {loss }}$ is the incident solar energy wich can be absorbed. The energy source is assumed to be reduced by a factor, generally of $5 \%$, the losses $Q_{\text {loss }}$ are mainly due to reflection by the glass (which receives $Q_{\text {glass }}=Q_{a b s}-Q_{C a b s}$ ) and dissipation to ambient air. Note that $A_{g}$ is the total area of the panel in $m^{2}$ with $\alpha_{g}\left(R_{H}, G, T_{a}\right) \simeq 0.95$ as absorption factor which may depend on $G, T_{a}, R_{H}$.

$$
\begin{gathered}
Q_{a b s}=Q_{\text {sun }}-Q_{\text {loss }} \\
Q_{a b s}=\alpha_{0} \cdot \alpha_{g}\left(R_{H}, G, T_{a}\right) \cdot A_{g} \cdot G
\end{gathered}
$$

The parameter $0=<\alpha_{0}<1$ depends on the incident angle.

$$
\begin{aligned}
& Q_{\text {glass }}=Q_{\text {abs }}-Q_{\text {Cabs }}-Q_{\text {glassoutput }} \\
& Q_{\text {glass }}=m_{g} \cdot c_{g} \cdot \frac{d T_{g}}{d t}+Q_{c g}+Q_{\text {Hloss }}
\end{aligned}
$$

Because of temperature difference between panel and ambient air, heat dissipates from the panel glass to outside via convection, conduction and radiation (see figure II.1).

The cells layer recieves $Q_{\text {Cabs }}$. At the cells layer the absorbed sun energy is received trough the glass (filtered) $Q_{\text {Cabs }}=\tau_{g} \alpha_{c} \cdot A_{c} \cdot G$, where $\tau_{g}$ is the glass transmissivity factor. The recieved power is converted in a thermal storage part $Q_{\text {Thermal }}=m_{c} \cdot c_{c} \frac{d T_{C}}{d t}$ which contributes to heating the 
cells layer and an electrical part $Q_{\text {Elect }}$ (electricity produced by the cells) with some losses noted $Q_{\text {Closs }}$.

$$
Q_{\text {Cabs }}=Q_{\text {Closs }}-Q_{\text {glassoutput }}+Q_{\text {Thermal }}+Q_{\text {Elect }}
$$

The electricity produced by energy conversion $Q_{\text {Elect }}$ is made of two parts: - the joule dissipation in the cells resistances $P_{j}$ and - the produced electricalpower $-P_{f}$. It is worthwhile to note that on the literature proposed models this part is neglected or not taken into account. In addition of this several assumptions are considered implicitly despite that they have consequences on the model precision and validity. We try to clarify this in the next section.

$$
Q_{c p}=Q_{p}+Q_{p i}+Q_{p f}+Q_{\text {glassoutput }}
$$

The plate receives $Q_{c p}$, consumes $Q_{p}=m_{p} \cdot c_{p} \frac{d T_{C}}{d t}$ and transmit $Q_{p i}=h_{p i} . A_{i} \cdot\left(T_{p}-T_{i}\right)$ to insulation layer and $Q_{p f}=$ $h_{p f} . A_{f} .\left(T_{p}-T_{f}\right)$ to the coolant fluid.

Let $h_{p f}$ be the convection heat transfer from the plate to the fluid. $h_{p f}=\left[\left(1 / h_{p}\right)+\left(1 / h_{f}\right)\right]^{-1}$ with $h_{f}=\frac{N u \cdot \lambda_{\text {eau }}}{D i}$ and $h_{p}=\frac{\lambda_{p}}{e_{p}}$, where $\nu \mathrm{Nu}$ is the Nussle number which is $\nu=4.36$ for a laminar flow, and $l_{\text {eau }}$ is the water thermal conductivity and $D_{i}$ the fluid pipe section diameter. $l_{p}$ and $e_{p}$ are the conductivity and thickness of the plate respectively. $h_{p i}$ is the conduction heat transfer factor from the plate to the insolation layer.

The joule heat generated by PV Cells is given by equation 10. The panel also heats due to internal Joule dissipation for the $\mathrm{N}$ cells of the panel $\left(N=N_{s} \cdot N_{p}\right.$ is total cells number). One part of the incident solar energy is absorbed by the PV cells and transformed in electricalpower $P$ plus a thermal dissipation (power losses $P_{j}$ ). Note that his power $P$ is consumed outside the PV panel and that the power loss represents a heat sink $P_{j}$ to the thermal system.

$$
\begin{gathered}
P_{j}=N R_{s} I^{2}+\frac{N\left(V+R_{s} I\right)^{2}}{R_{s h}} \\
P_{j}=N R_{s}\left(I_{p h}-I_{s}\left[e^{\left(\frac{q\left(V+R T_{s} I\right)}{n k T_{c}}\right)}-1\right]-\frac{\left(V+R_{s} I\right)}{R_{s h}}\right)^{2}+\frac{N\left(V+R_{s} I\right)^{2}}{R_{s h}}(11)
\end{gathered}
$$

The internal heat sources of the panel is due to the Joule effect of the series and shunt resistors. In fact, current passing through the printed $\mathrm{Ag}$ fingers and through the $\mathrm{Cu}$ bus-bars will lead to a localized heat generation modeled by the series resistor $R_{s}$. Besides, current passing through a path around the cell will lead to a localized heat generation modeled by the series resistor $R_{s h}$. The power loss is dissipated by the cells resistors $R_{s}$ and $R_{s h}$, of each cell. This will have influence on the cell layer temperature.

\section{B. Thermal Model of the Glazed PVT collector}

The thermal behavior may be described by the equations (5-9), gathering the fluxes imposed to the PVT system [13]. In what follows, use of averaged efficiency factor is avoided. Note that thermal and electrical efficiencies are defined only in a steady state operation mode (for averaged behavior) and not valid in the transient periods. a) Glass Model: Let $m_{g}$ and $c_{g}$ be the glass mass in $\mathrm{kg}$ and thermal specific heat (thermal capacity in $J . K g^{-1} \cdot K^{-1}$ ) respectively. The glass thermal behavior can be summarized by equation 12 :

$$
\begin{array}{r}
m_{g} \cdot c_{g} \cdot \frac{d T_{g}}{d t}+h_{c g} \cdot A_{g} \cdot\left(T_{g}-T_{c}\right)+\sigma \cdot \varepsilon_{g} \cdot\left(T_{g}{ }^{4}-T_{a}{ }^{4}\right) \\
=-h_{g a} \cdot A_{g} \cdot\left(T_{g}-T_{a}\right)+\alpha_{g} \cdot A_{g} \cdot G-Q_{C a b s}
\end{array}
$$

b) PV Cells Thermal Model: The dynamic heat transfer in the cells is described by the following equation. The absorbed thermal energy in the cells layer is

$$
\begin{array}{r}
Q_{P V \text { cells }}=m_{c} \cdot c_{c} \cdot \frac{d T_{c}}{d t}=Q_{C a b s}+Q_{c g}+Q_{\text {Elect }}-Q_{c p} \\
Q_{\text {Elect }}=P_{j}-P \\
m . c_{c} \cdot \frac{d T_{c}}{d t}+h_{c g} \cdot A_{g} \cdot\left(T_{c}-T_{g}\right)+h_{c p} \cdot A_{p} \cdot\left(T_{c}-T_{p}\right) \\
=\tau_{g} \alpha_{c} \cdot A_{c} \cdot G+Q_{\text {Elect }}
\end{array}
$$

c) Plate thermal storage: The plate is used to catch the heat flow coming from the PV cells and the sun trough the glass and transmit it to the fluid. The absorbing plate collects thermal energy dissipated by the sun and cells and transfers it to the coolant fluid. This leads to a decrease of the cells temperature and then increases the PV efficiency. Its dynamic equation $Q_{\text {Plate }}=m_{p} \cdot c_{p} \cdot \frac{d T_{p}}{d t}$ can be written:

$$
\begin{array}{r}
m_{p} \cdot C_{p} \cdot\left(d T_{p} / d t\right)+h_{c p} \cdot A_{p} \cdot\left(T_{p}-T_{c}\right)+h_{p i} \cdot A_{p} \cdot\left(T_{p}-T_{i}\right) \\
=-h_{p f} \cdot A_{f} \cdot\left(T_{p}-T_{\text {fout }}\right)
\end{array}
$$

d) Fluid Thermal Equation: The fluid temperature behavior is governed by the following equation where the fluid output temperature $T_{\text {fout }}$ depends strongly on the plate temperature $T_{p}$, the inlet fluid temperature $T_{f i n}$ and the liquid flow $\dot{m}$. Where $m_{f}$ is the fluid mass (in the exchanger) and $c_{f}$ the specific heat of the coolant fluid. We have $Q_{p f}=$ $h_{p f} \cdot A_{f} \cdot\left(T_{p}-T_{f}\right)$ and $Q_{u}=\dot{m} . c .\left(T_{\text {fout }}-T_{\text {fin }}\right)$.

$$
m_{f} \cdot C_{f} \cdot \frac{d T_{f}}{d t}+h_{p f} \cdot A_{f} \cdot\left(T_{f}-T_{p}\right)=-\dot{m} . c .\left(T_{f}-T_{f i n}\right)
$$

\section{e) Insulation layer Thermal Equation:}

$Q_{p i}=h_{p i} \cdot A_{i} \cdot\left(T_{p}-T_{i}\right)$, is the heat flow from the plate to the insolation with $h_{p i}=\left[\left(1 / h_{p}\right)+\left(1 / h_{i}\right)\right]^{-1}$

$$
Q_{\text {Isto }}=m_{i} \cdot c_{i} \cdot \frac{d T_{i}}{d t}=Q_{p i}-Q_{i a}
$$

$$
m_{i} \cdot c_{i} \cdot \frac{d T_{i}}{d t}=h_{p i} \cdot A_{i} \cdot\left(T_{p}-T_{i}\right)-h_{i a} \cdot A_{i} \cdot\left(T_{i}-T_{a}\right)
$$

\section{Thermal Model of the Unglazed PVT}

In the case of an unglazed PVT panel, the first equation (Glass) is droped because there is no glass. The remaining equations are more or less the same mutadis mutandi. 


$$
\begin{gathered}
m_{c} c_{c} \frac{d T_{c}}{d t}=\alpha_{c} G A_{c}+N R_{s} I^{2}+N \frac{\left(V+R_{s} I\right)^{2}}{R_{s h}}-N V I \\
+h_{c p} A_{c}\left(T_{c}-T_{p}\right)-\left(h_{c a}-h_{c a r}\right) A_{c}\left(T_{c}-T_{p}\right) \\
m_{p} c_{p} \frac{d T_{p}}{d t}=h_{c p} A_{c}\left(T_{c}-T_{p}\right)-h_{p f} A_{p}\left(T_{p}-T_{f}\right)-h_{p i} A_{i}\left(T_{p}-T_{i}\right) \\
m_{f} c_{f} \frac{d T_{f}}{d t}=h_{p f} A_{f}\left(T_{p}-T_{f}\right)-\dot{m}_{f} A_{p}\left(T_{f o u t}-T_{f i n}\right) \\
m_{i} c_{i} \frac{d T_{i}}{d t}=h_{p i} A_{i}\left(T_{p}-T_{i}\right)-\left(h_{i a}-h_{\text {iar }}\right) A_{i}\left(T_{i}-T_{a}\right)
\end{gathered}
$$

Where $\mathrm{h}_{\mathrm{car}}=\varepsilon_{c} \sigma\left(T_{c}{ }^{2}+T_{a}{ }^{2}\right)\left(T_{c}+T_{a}\right)$ is the radiation heat loss coefficient. $\mathrm{h}_{\mathrm{pf}}=\left[\frac{e_{c}}{\lambda_{c}}+\frac{D_{i}}{N_{u} K_{w}}\right]^{-1}$ is the convective heat transfer coefficient between the plate and the fluid.

$\mathrm{h}_{\mathrm{ip}}=\frac{\lambda_{i}}{e_{i}}$ is the conduction heat transfer coefficient between cells and the plate and $\mathrm{h}_{\mathrm{pi}}=\left[\frac{e_{c}}{\lambda_{c}}+\frac{e_{i}}{\lambda_{i}}\right]^{-1}$ is the heat transfer coefficient between thermal plate and insulation.

\section{Controlled part and State Space variables}

1) Pump Control: The fluid flow is given by a pump controlled by a voltage input $u_{p}$. The liquid flowing in the PVT collector circulates with the flow rate $\dot{m}$ which is in general controlled by a pump driven by an electrical motor which can be represented by the following equations where the pump rotation velocity is noted $\Omega$. In general we can assume that the flow is proportional to the rotation velocity of the pump $\dot{m}=k \Omega$. Then we get the mechanical equation of the pump rotation and its driving motor

$$
J \frac{d \Omega}{d t}+f \Omega=C_{e m}-C_{r}
$$

The pump mechanical load imposed to the motor is considered to be proportional to the squarred velocity $C_{r}=k_{r} \Omega^{2}$ then we get the state equation governing the flow rate as follows, where the current $i_{\text {pump }}$ is an input used to control the flow rate.

$$
\begin{gathered}
J \ddot{m}+\left(f+k_{r} \dot{m}\right) \dot{m}=K_{\text {pump }} u_{p} \\
\ddot{m}=-\frac{\left(f+k_{r} \dot{m}\right)}{J} \dot{m}+\frac{K_{\text {pump }}}{J} \cdot u_{p}
\end{gathered}
$$

2) The electrical power: The serial resistance $R_{S}$ relative to one cell in open circuit voltage $V_{O C}$ is:

$$
R_{S}=\left.\frac{d V}{d I}\right|_{V_{O C}}=\left(\frac{n k T_{1, r e f}}{q}\right) /\left(I_{0}\left(T_{1, r e f}\right) e^{\frac{\frac{V_{O C}\left(T_{1, r e f}\right)}{n k T_{1, \text { ref }}}}{q}}\right)
$$

The shunt resistance is considered inversely proportional to the absorbed solar radiation,

$$
R_{\text {sh }}=R_{\text {shref }} \frac{G_{r e f}}{G}
$$

The Current generated by one PV cell is

$$
I=I_{p h}-I_{s} \cdot\left[e^{\left(\frac{q(V+R s \cdot I)}{n k T_{c}}\right)}-1\right]-\frac{\left(V+R_{s} \cdot I\right)}{R_{s h}}
$$

The photo-current $I_{p h}$ and the reverse saturation diode current $I_{s}$ depends on the cell junction temperature $T_{c}$ [Ref 10],

$$
\begin{aligned}
& I_{s}=I_{s_{r e f}} \cdot\left(\frac{T_{c}}{T_{r e f}}\right)^{3} \cdot e^{\left(q \cdot E_{g} \cdot \frac{\left(\left(\frac{1}{T_{r e f}}\right)-\left(\frac{1}{T_{c}}\right)\right)}{(n \cdot k)}\right)} \\
& \left.I_{p h}=\left[I_{p h_{r e f}}-C_{i} \cdot\left(T_{c}-T_{r e f}\right)\right] \cdot \frac{G}{G_{r e f}}\right)
\end{aligned}
$$

Equation (28) shows that the electrical efficiency of the system decreases when the temperature of the junction of the cells increases. $C_{i}$ is a positive coefficient and $T_{r e f}$ the reference temperature defined as $25^{\circ} \mathrm{C}$ in general. The circulation of the coolant in the PVT panel lowers the cells temperature and thus it improves the electrical performance of the PV system.

The produced electrical power model $P_{\text {elec }}=I . V$ is given by its time variation ( $V$ come from the $\mathrm{N}$ cells of the panel):

$$
\begin{gathered}
\frac{d P_{\text {elec }}}{d t}=I \cdot \frac{d V}{d t}+V \cdot \frac{d I}{d t}=I \cdot u_{1}+V \cdot u_{2} \\
\frac{d P_{\text {elec }}}{d t}=\left(I_{p h}-I_{s}\left[e^{\left(\frac{q(V+R s . I)}{n k T_{c}}\right)}-1\right]-\frac{\left(V+R_{s} I\right)}{R_{s h}}\right) u_{1}+V u_{2}
\end{gathered}
$$

To reach the operating point $\left(V_{\text {optim }}, I_{\text {optim }}\right)$ giving the Maximum Power (MPP), we can use the control imputs $u_{1}$ or $u_{2}$, or both alternatively. See for details [15], [23]. In a first case, the current may be fixed constant and set $u_{2}=0$. The control will be $u_{1}(k)=f(\triangle V(k))$

The PV output current $I$ goes through a boost converter to control the input voltage $\mathrm{V}$. The current $i_{L}$ flowing from the boost converter output, in the load assumed to be $Z_{L}$ is .

$$
V=Z_{L} i_{L}
$$

If the load $Z_{L}$ is an $R-L$ equivalent circuit, for the sake of simplicity, we can write $R i_{L}+L \frac{d i_{L}}{d t}=v_{o}$ and then we get an equation defining a new additional state variable, which can be considered in the system model.

$$
\frac{d i_{L}}{d t}+\frac{R}{L} i_{L}=\frac{V}{L}
$$

\section{E. System State Space Representations}

1) Glazed PVT Model: Let us consider the state vector defined as $X=\left[T_{g}, T_{c}, T_{p}, T_{f}, T_{i}, m, P_{\text {elec }}, i_{L}\right]^{T}$ and the input control vector $U=\left[u_{p}, u_{1}, u_{2}\right]^{T}$

To get a state space representation of the process,

$$
\left\{\begin{array}{l}
\dot{X}=f\left(X, T_{a}, G, R_{H}\right)+g\left(u_{p}, u_{1}, u_{2}\right) \\
y=h(X)
\end{array}\right.
$$

we gather the equations (12),(15), (16), (17), (19), (22), (30) and (32).

2) Unglazed PVT Model: In the case of an unglazed PVT panel the state vector will be $X_{u}=\left[T_{c}, T_{p}, T_{f}, T_{i}, m, P_{\text {elec }}, i_{L}\right]^{T}$ the same and the input control vector $U=\left[u_{p}, u_{1}, u_{2}\right]^{T}$.

The model gathers the equations (20),(22), (30) and (32). 


\section{PV/T PERFORMANCE EVALUATION}

\section{A. Unglazed PVT Model Validation}

For validation of our models, we consider the unglazed $\mathrm{PV} / \mathrm{T}$ Wave proposed by DualSun. This hybrid panel is unglazed and it has an area of $1.604 \mathrm{~m}^{2}$. The mono-crystalline cells encapsulated in EVA (Ethylene - Vinyl - Acetate) and TPT (Tedlar - polyester - Tedlar). This encapsulation ensures protection for cells and electrical insulation with other constituent. The thermal plate made of aluminum is totally covered by cells and so the excess of heat generated by cells is the input of the thermal part. The cells are integrated with the thermal part by pasting it on the absorber plate. The fluid ducts are welded in the back surface of plate and arranged with equal spacing between the tubes. Insulation is used to limit the back thermal losses. The electrical data of the solar cells under standard test conditions (STC) are given in the following table (IV-A).

\begin{tabular}{cccc}
\hline parameters & values & & \\
\hline \hline Number of cells & 60 & Cell thickness & $0.0002 \mathrm{~m}$ \\
\hline Electrical efficiency & $15.4 \%$ & Plate thickness & $0.0004 \mathrm{~m}$ \\
\hline Open circ.Volt (Vco) & $38.5 \mathrm{v}$ & Insulation thickness & $0.02 \mathrm{~m}$ \\
\hline Short circ.Curr. (Isc) & $8.55 \mathrm{~A}$ & Coolant Fluid & glycol \\
\hline Temperature NOCT & $46^{\circ} \mathrm{C}$ & Fluid mass & $1.7 \mathrm{~kg}$ \\
\hline Rs & $0.01 \Omega$ & F Specific heat & $3605 \mathrm{~J} / \mathrm{kg} . \mathrm{K}$ \\
\hline Rsh & $260 \Omega$ & TABLE L &
\end{tabular}

PVT PARAMETERS

The numerical model of the unglazed PVT was validated based on the Data -sheet of Dualsun [DualSun] (see figure IV-A). It presents a steady state indoor experimental results done by TUV Rheinland Lab-Germany under conditions prescribed by EN12975 standards: $G=850 \mathrm{~W} / \mathrm{m}^{2}, v_{w}=1 \mathrm{~m} / \mathrm{s}$ and $T_{\text {fin }}$ varying from $20^{\circ} \mathrm{C}$ to $55^{\circ} \mathrm{C}$. Let us note $T_{\text {red }}=$ $T_{\text {fout }} / G$.

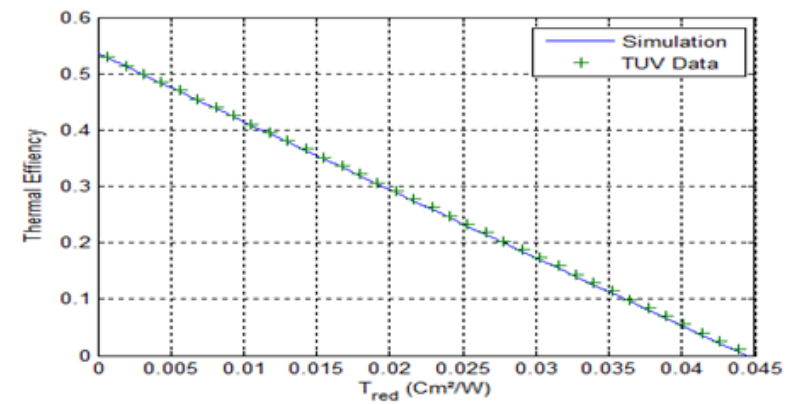

Fig. IV.1. Thermal efficiency for steady state conditions $T_{\text {red }}=T_{\text {fout }} / G$

The simulation results, using the proposed model, show very good agreement with the experimental results given by TUV Rheinland Lab as shown in the figure (IV-A).

\section{B. Performance Evaluation}

The main interest of this study is to find a good combination of materials that ensures the optimal performances and reduces the price of the actual device. Simulation tests were carried out to compare the thermal behavior of PV/T using different materials for the absorber plate, cells type and with or without a glass under the steady state conditions of $\mathrm{G}=1000 \mathrm{~W} / \mathrm{m}^{2}$, $\mathrm{Ta}=25^{\circ} \mathrm{C}$, and a flow rate equal to $0.05 \mathrm{Kg} / \mathrm{s}$. Varying the parameters is done, in simulations, to obtain an optimal design for the system.

Many studies in the literature led to consider that polymer is one of the most promising material used to reduce the cost and the weight of the device. We tested at first, under the steady state conditions, the PVT panel with additional glass cover and compare it performances to the Unglazed PVT wave. The electrical efficiency of the PV/T cells (see figure IV-B) may be calculated by:

$$
\eta_{e l}=\frac{V I}{A_{c} G}
$$

The thermal efficiency (compared for glazed and unglazed PVT in figure IV-B) is defined as the ratio of the thermal yield and the total incident energy:

$$
\eta_{t h}=\frac{\dot{m} c_{f}\left(T_{\text {fout }}-T_{\text {fin }}\right)}{A_{p} G}
$$

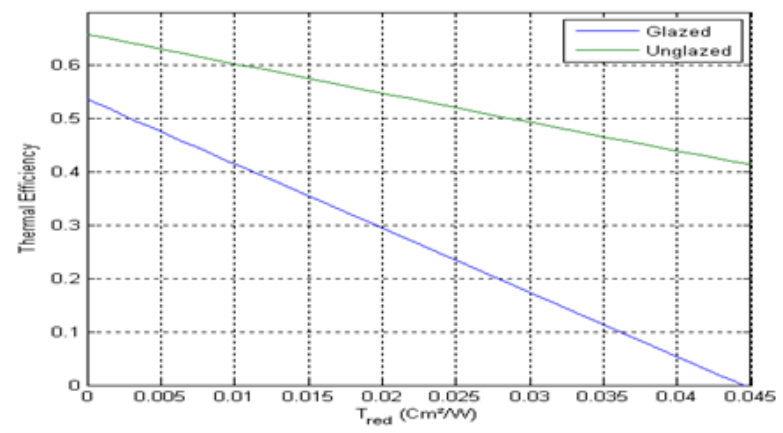

Fig. IV.2. Thermal efficiency for glazed and unglazed PV/T.

The glazed PVT presents a remarkably higher thermal efficiency, thus due to the presence of glass layer that limits the convective losses (see figure IV-B). But the electrical efficiency deteriorates due to the higher operating cells temperature and to the additional optic losses. This is also may accelerae the cells aging.

A second test was carried out under the steady state conditions to compare performances of unglazed PVT Dualsun using other materials for the thermal plate :(1) Copper, and (2) Polymer. (in the actual design Aluminum was used).

As it can be shown in the figure (IV-B) and (IV-B), materials with higher thermal conductivity (in this case copper and aluminum) can transfer heat easily from the cells to the fluid as a result the thermal efficiency is remarkably higher. Also the cells operating temperature is nearly 4 degrees higher in the case of polymer PPO, and this leads to have the electrical efficiency is slightly lower than copper and aluminum PVT.

A third test was carried out to study the cells type effect on system performances. For the actual Dualsun Panel, single crystalline cells are used with $\eta_{\mathrm{o}}$ slightly higher than $15 \%$ but they are more sensible to operating temperature. A simulation 


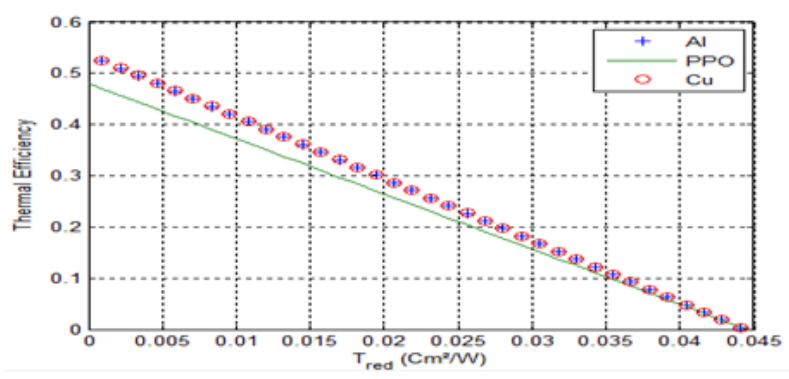

Fig. IV.3. Thermal efficiency for different materials.

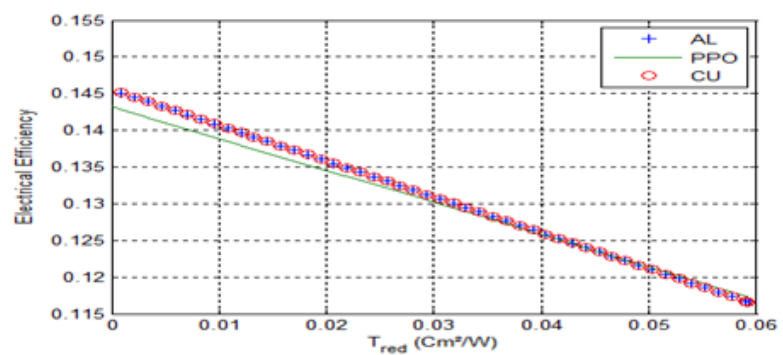

Fig. IV.4. Electrical efficiency for different materials.

test was carried out to compare the different kind of thermal plates seen previously combined with both single crystalline cells and thin film cells (see figures IV-B, IV-B and IV-B).

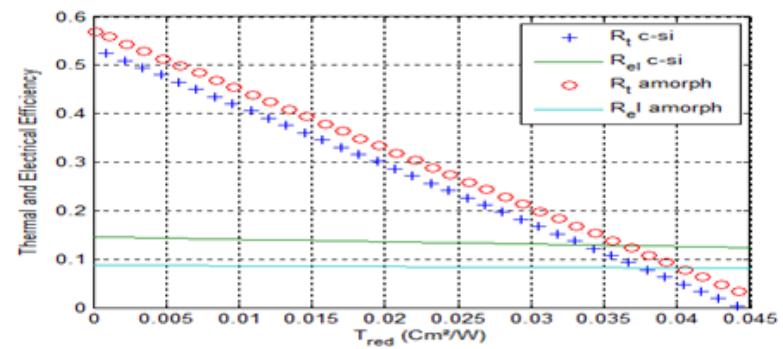

Fig. IV.5. Electrical and thermal efficiency for Aluminum plate.

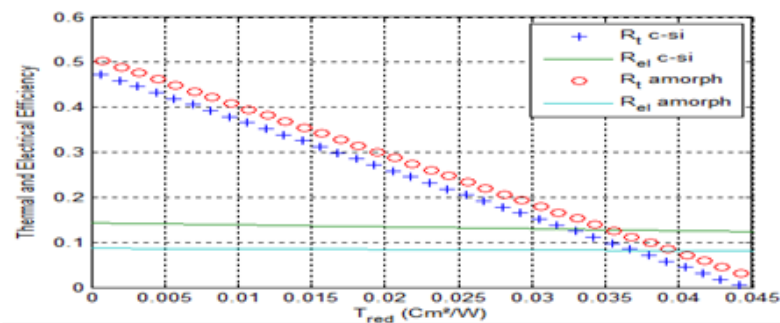

Fig. IV.6. Electrical and thermal efficiency for Polymer plate

As shown in figures IV-B, IV-B and IV-B, the efficiency of the amorphous cells is less sensible to temperature. Their electrical efficiency lower than the silicon cells, meaning less amount of absorbed energy is converted to electricity and so more available energy for heat production. As result thermal efficiency for thin film cells in three cases is higher It's possible also to notice that in three cases the electrical efficiency for a chosen type of cells is practically the same. The thermal efficiency is slightly lower for the PPO. Semitransparent Thin film cells can be used in order to improve the global efficiency of the system. Extra solar radiation with

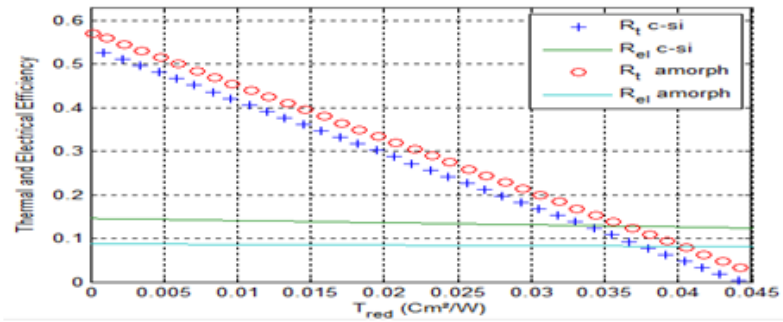

Fig. IV.7. Electrical and thermal efficiency for copper plate.

low energy long wave, not absorbed by cells, like infrared radiation can reach the thermal absorber and contribute in heating the fluid unlike classic cell where the infrared radiation are reflected. As shown in the figures IV-B, IV-B and IV-B with semi transparent cells the thermal efficiency is more important than the same type classic cells.

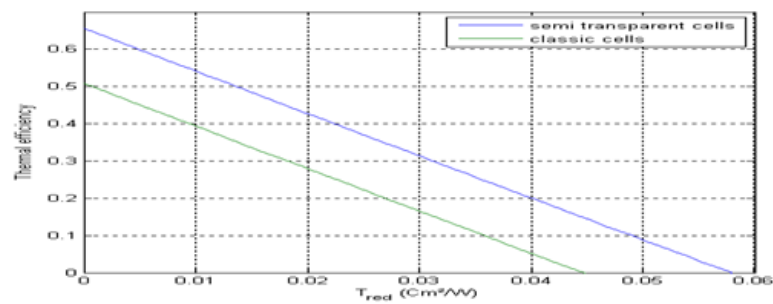

Fig. IV.8. Thermal efficiency for semitransparent cells against classic cells.

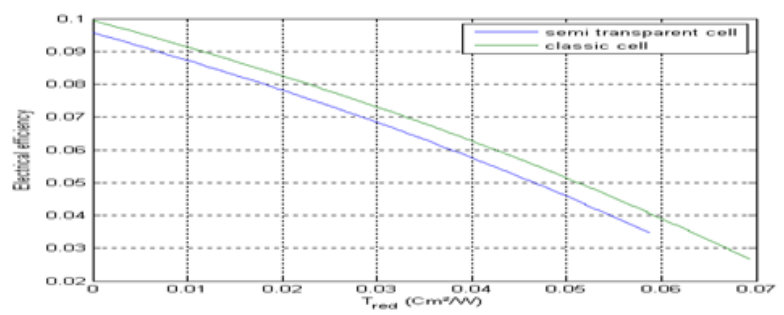

Fig. IV.9. Electrical efficiency for transparent cells against classic cells.

With the semi-transparent cells, the plate temperature is higher resulting from the extra absorbed infrared radiations. Since they are pasted directly on the plate, the cells have a higher temperature than the classic cells and slightly lower electrical efficiency fig. 13.

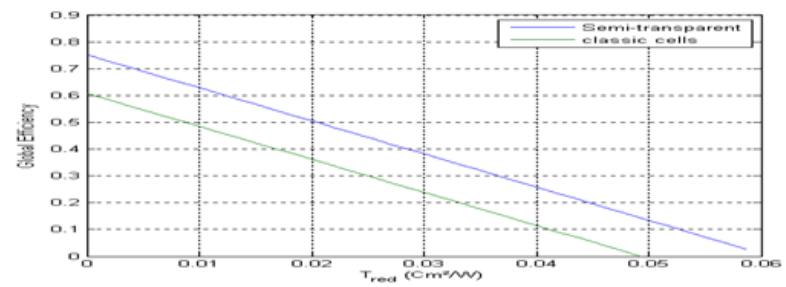

Fig. IV.10. Global efficiency for semitransparent cells.

The global efficiency of the PV/T using semi-transparent is higher than the PVT with classic cells.

\section{Maximum Life Span Power Point}

Let us consider again the figure (IV-C) comparing the cells temperature variation for PVTs with different materials. We 
then remark that near the Maximum Power Point (in brown) there is a minimum of the temperature. At this point the power produced is reduced by $5 \%$ to $10 \%$ which is not to penalizing. The cells temperature may decrease from some degrees (depending on the PV nature and fluid circulation) and this may be more comfortable situation for the cells operation. We have then defined this as the Maximum Life Span Power Point (MLSPP) to increase the PVT life time, by limiting cells heating regarding to their State of Health $(\mathrm{SoH})$.

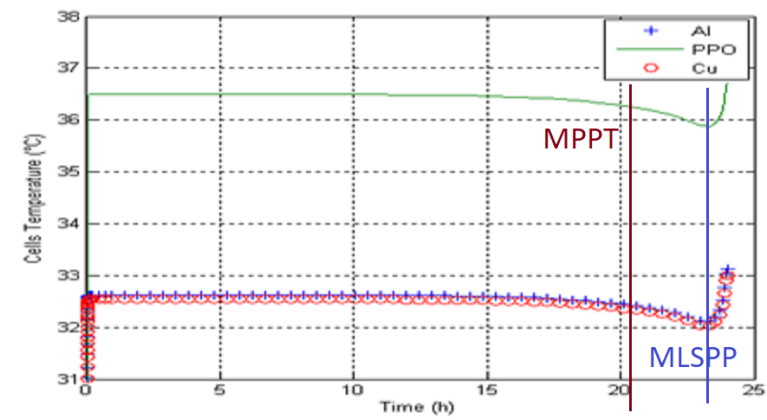

Fig. IV.11. Cells temperature for different materials.

The Maximum Life Span Power Point (MLSPP) allows to drive the system to an operational point with maximum efficiency while keeping the process in healthy comfortable situation. Doing this reduces the produced power of around $10 \%$ only. Anyway this feature can be interestingly used in advanced system control.

\section{Conclusion}

We have developed PVT models, in glazed and unglazed cases, for numerical systems prototyping, analysis and control. With those models, it was possible to study the effect of different key parameters on the system performance; with or without glass cover, cells type, and material used for thermal plate. The design and the structure of the PVT device depends mainly on the application for which it is intended: hot water is more important or electricity.

From the simulation results, it's possible to conclude that Polymer was as much efficient as aluminum and copper. It may be a good substitute for aluminum in the actual commercialized PVT: Reduces the weight of the device, and reduces manufacturing cost. Also, it's more suitable to keep using mono-crystalline cells for their low operating temperature.

The state space formulation of these models opens interesting perspectives for advanced non linear control and energy management. We have then defined this as the MLSPP which allows to increase the PVT life time, by limiting cells heating to acceptable values regarding to their State of Health $(\mathrm{SoH})$.

\section{REFERENCES}

[1] A. R. Garg HP, "Transient simulation of conventional hybrid photovoltaic/thermal air heating collectors," 1998.

[2] Y. Tripanagnostopoulos, T. Nousia, M. Souliotis, and P. Yianoulis, "Hybridphotovoltaic thermal solar systems," Solar Energy, no. 6, pp. 217-234, 2002.

[3] Y. Tripanagnostopoulos, M. Bazilian, I. Zoulia, and R.Battisti, Hybrid PV/T System with Improved Air Heat Extraction Modification.
[4] O. L. T. Bergene, "Model calculations on a flat-plate solar heat collector with integrated solar cells," Solar Energy, no. 55, pp. 453-462, 1995.

[5] H. Garg and P. Agarwal, "Photovoltaic-thermosyphon water heating system for residential application," Energy Conversion and Management, no. 36, pp. 87-99, 1995.

[6] B. Huang, T. Lin, W. Hung, and F. Sun, "Performance evaluation of solar photovoltaic/thermal systems," Solar Energy, no. 70, pp. 443-448, 2001.

[7] K. M. E. Orda, "Low-tech solar thermal water pumps for use in developing countries," Solar Energy, pp. 768-773, 2004.

[8] A. Tiwari and M. Sodha, "Performance evaluation of hybrid pv/thermal water/air heating system a parametric study," Renewable energy, pp. 2460-2474, 2006.

[9] H. Zondag, D. D. vries, and W. J. V. Helden, "The yield of different combined pv-thermal collector designs," Solar Energy, vol. 74, pp. 253$269,2003$.

[10] G. Tina and S. Scrofani, "Electrical and thermal model for pv module temperature evaluation," in Electrotechnical Conference, 2008. MELECON 2008. The 14th IEEE Mediterranean. IEEE, 2008, pp. 585-590.

[11] M. Rosa-Clot, P. Rosa-Clot, and G. Tina, "Tespi: thermal electric solar panel integration," Solar Energy, vol. 85, no. 10, pp. 2433-2442, 2011.

[12] Bhaskrab, "Hybrid photovoltaic thermal system : A state- of the-art literature review."

[13] L. Bonsignore, M. Davarifar, A. Rabhi, G. M. Tina, and A. Elhajjaji, "Neuro-fuzzy fault detection method for photovoltaic systems," Energy Procedia, vol. 62, pp. 431-441, 2014.

[14] M. S. A. Tiwari, Bhaskrab Hybrid Photovoltaic Thermal System : A State- of the-Art Literature Review.

[15] N. M'Sirdi, B. Nehme, M. Abarkan, and A. Rabbi, "The best mppt algorithms by vsas approach for renewable energy sources (res)," in EFEA 2014, Paris France, 19-21 November 2014, pp. 1-7.

[16] T. Chow, "Dynamic performance of hybrid photovoltaic thermal collector wall in hong kong."

[17] C. Cristofari, G. Notton, and J. Canaletti, "Thermal behavior of a copolymer pvt solar system in low flow rate conditions," Solar Energy, vol. 83, no. 8, pp. 1123-1138, 2009.

[18] B. Nehme, N. MSirdi, and T. Akiki, "Assessing the effect of temperature on degradation modes of pv panels," in Conference MedICT 2015, Oujda Moroco, 2015.

[19] S. Armstrong and W. Hurley, "A thermal model for photovoltaic panels under varying atmospheric conditions," Applied Thermal Engineering, vol. 30, no. 11, pp. 1488-1495, 2010.

[20] A. Jones and C. Underwood, "A thermal model for photovoltaic systems," Solar energy, vol. 70, no. 4, pp. 349-359, 2001.

[21] M. Mattei, G. Notton, C. Cristofari, M. Muselli, and P. Poggi, "Calculation of the polycrystalline $\{\mathrm{PV}\}$ module temperature using a simple method of energy balance," Renewable Energy, vol. 31, no. 4, pp. 553 - 567, 2006. [Online]. Available: http://www.sciencedirect. com/science/article/pii/S096014810500073X

[22] B. W. A. Duffie JA, Solar Engineering of Thermal Processes, wiley ed., 2013.

[23] N. MSirdi, B. Nehme, M. Abarkan, and A. Rabbi, "The vsas approach gives the best mppt for solar energy sources (res)," in Mediterranean Green Energy Forum MGEF 2015. Marrakech, Morocco: 2rd International conference:Mediterranean Green Energy Forum, 26-28 March 2015, pp. 1-7. 